\title{
Chi3|3: a potential key orchestrator of eosinophil recruitment in meningitis induced by Angiostrongylus cantonensis
}

Shuo Wan ${ }^{1,2,3 \dagger}$, Xiaoqiang Sun ${ }^{2,5+}$, Feng Wu ${ }^{4 \dagger}$, Zilong Yu ${ }^{1,2,3}$, Lifu Wang ${ }^{1,2,3}$, Datao Lin ${ }^{1,2,3}$, Zhengyu Li ${ }^{6}$, Zhongdao $\mathrm{Wu}^{1,2,3^{*}}$ and Xi Sun ${ }^{1,2,3^{*}}$ (D)

\begin{abstract}
Background: Angiostrongylus cantonensis, an important foodborne parasite, can induce serious eosinophilic meningitis in non-permissive hosts, such as mouse and human. However, the characteristics and mechanisms of the infection are still poorly understood. This study sought to determine the key molecules and its underlying mechanism in inducing brain eosinophilic infiltration caused by Angiostrongy/us cantonensis.

Methods: Mathematical models were established for prediction of significantly changing genes and the functional associated protein with RNA-seq data in Angiostrongylus cantonensis infection. The expression level of Chi3l3, the predicted key molecule, was verified using Western blotting and real-time quantitative PCR. Critical cell source of Chi3l3 and its relationship with eosinophils were identified with flow cytometry, immunohistochemistry, and further verified by macrophage depletion using liposomal clodronate. The role of soluble antigens of Angiostrongylus cantonensis in eosinophilic response was identified with mice airway allergy model by intranasal administration of Alternaria alternate. The relationship between Chi3/3 and IL-13 was identified with flow cytometry, Western blotting, and Seahorse Bioscience extracellular flux analyzer.

Results: We analyzed the skewed cytokine pattern in brains of Angiostrongylus cantonensis-infected mice and found Chi3/3 to be an important molecule, which increased sharply during the infection. The percentage of inflammatory macrophages, the main source of Chi3/3, also increased, in line with eosinophils percentage in the brain. Network analysis and mathematical modeling predirect a functional association between Chi3/3 and IL-13. Further experiments verified that the soluble antigen of Angiostrongylus cantonensis induce brain eosinophilic meningitis via aggravating a positive feedback loop between IL-13 and Chi3l3.

Conclusions: We present evidences in favor of a key role for macrophave-derived Chi3/3 molecule in the infection of Angiostrongylus cantonensis, which aggravates eosinophilic meningitis induced by Angiostrongylus cantonensis via a IL-13-mediated positive feedback loop. These reported results constitute a starting point for future research of angiostrongyliasis pathogenesis and imply that targeting chitinases and chitinase-like-proteins may be clinically beneficial in Angiostrongylus cantonensis-induced eosinophilic meningitis.
\end{abstract}

Keywords: Brain, Eosinophilic infiltration, Macrophage, Polarization, Soluble antigens of A. cantonensis larvae (L4) (sAg), Chi3|3-IL-13

\footnotetext{
*Correspondence: wuzhd@mail.sysu.edu.cn; sunxi2@mail.sysu.edu.cn

${ }^{\dagger}$ Equal contributors

${ }^{1}$ Department of Parasitology of Zhongshan School of Medicine, Sun Yat-sen

University, No.74 Zhongshan Road.2, Guangzhou, Guangdong 510080, China

Full list of author information is available at the end of the article
}

(c) The Author(s). 2018 Open Access This article is distributed under the terms of the Creative Commons Attribution 4.0 International License (http://creativecommons.org/licenses/by/4.0/), which permits unrestricted use, distribution, and reproduction in any medium, provided you give appropriate credit to the original author(s) and the source, provide a link to the Creative Commons license, and indicate if changes were made. The Creative Commons Public Domain Dedication waiver (http://creativecommons.org/publicdomain/zero/1.0/) applies to the data made available in this article, unless otherwise stated. 


\section{Background}

Angiostrongylus cantonensis (A. cantonensis, AC), a rat lung nematode, is a serious foodborne parasite. It occurs in Asia, the Pacific islands, Australia, and the Caribbean islands [1]. Humans and mice, non-permissive hosts, become infected by eating raw intermediate hosts, including Pomacea canaliculate and Ampullaria crossean [2]. In recent years, due to the wide spread of snails and slugs, the disease is no longer restricted to certain areas $[3,4]$. AC has become a major threat to both human beings and wildlife species globally. Two nine-banded armadillos and one Virginia opossum were reported to be infected with $\mathrm{AC}$ in the southeastern USA [5]. According to a review published in 2008, nearly 3000 cases of human angiostronglyiasis had been documented worldwide [6]; however, this number has risen rapidly. In a prospective descriptive study conducted from June 2008 to January 2014 in a Vietnamese hospital, AC was an important cause of eosinophilic meningitis, accounting for $67.3 \%(37 / 55)$ of cases [7].

Most individuals develop eosinophilic meningitis when infected with $\mathrm{AC}$, and common clinical symptoms include headache, neck stiffness, paresthesia, vomiting, and nausea. Furthermore, if the worms move to the eyes, ocular angiostrongyliasis may occur, causing visual disturbances. Additionally, surgery must be performed to remove the worms from the eyes of patients with ocular angiostrongyliasis [8]. Thus far, treatment of angiostrongyliasis is still limited. Traditional anthelmintic drugs, such as albendazole and mebendazole, are not recommended for angiostrongyliasis treatment, as they may exacerbate neurological symptoms [9].

Although AC may produce severe neurological disease, little is known about its underlying pathogenic mechanisms. It is widely assumed that type 2 immunity, a major protective mechanism against helminth infection, such as filarial nematode Brugia malayi [10], Nippostrongylus brasiliensis [11], Trichinella spiralis [12], Schistosoma japonicum [13], and Heligmosomoides polygyrus [14], is involved in the process of helminth infection. And IL-5 [15, 16], IL-13 [17], and Eotaxin [18, 19] are currently regarded as the common characteristics in eosinophilic infiltration-related diseases. Unexpectedly, Mesocestoides corti infection in IL-5 knockout mice resulted in normal blood and tissue eosinophil levels [20]. In addition, knockout of Eotaxin [21] partially reduced antigen-induced tissue eosinophilia. CCR3 [22, 23], as the receptor of Eotaxin, also played an important role in eosinophil migration to injured tissues, suggesting that other factors may participate in eosinophil infiltration as well.

Chi313, an unconventional eosinophil-related protein [24], is highly expressed in Th2 type immune responses caused by helminth infections and allergic diseases. Here, we identified burst expression of Chi3l3 as a useful discriminative marker between the non-permissive host and permissive host, as well as a key player during AC infection in the non-permissive mouse model host. We also investigated its biological function during $\mathrm{AC}$-induced eosinophilic meningitis.

\section{Methods \\ Preparation of soluble antigens of $\mathrm{AC}(\mathrm{sAg})$ and bone marrow-derived macrophage (BMDM) cells}

Soluble antigens of the 4th stage larvae of AC (AC L4) were collected from Sprague-Dawley rat brains at $21 \mathrm{dpi}$ as previously described [25]. Bone marrow cells were isolated as described previously [26] and cultured with M-CSF $(20 \mathrm{ng} / \mathrm{mL})$ in complete medium [DMEM High Glucose, $100 \mathrm{U} / \mathrm{ml}$ of penicillin-streptomycin and $10 \%$ heat-inactivated $\left(56{ }^{\circ} \mathrm{C}, 30 \mathrm{~min}\right) \mathrm{FBS}$ ] for 7 days. The following reagents were used in this study: Recombinant Murine M-CSF (315-02; Peprotech), Recombinant Mouse Chi3l3 (2446-CH-050, R\&D Systems), and Recombinant Mouse IL-13 (413-ML-025/CF, R\&D Systems).

\section{Establishment of airway allergy and AC infection models}

For establishment of the airway allergy model, female C57 mice were chosen, and Alternaria alternata (Greerlabs, Lenoir, NC, $100 \mathrm{~g} /$ mouse in $50 \mu \mathrm{L}$ ) or PBS $(50 \mu \mathrm{L})$ was administered intranasally on four consecutive days [27]. Four hours before the daily Alternaria alternata administration, $50 \mu \mathrm{g}$ soluble rat-derived antigens of AC larvae (L4) or an equal volume of PBS treatment was administered via nasal drip. On the day after the last intranasal stimulation, mice were euthanized and BAL was harvested. Then, the cells derived from BAL were stained by Siglec F PE (BD), CD11c PECyanine5 (eBioscience), or CD45 APC-cy7 (Biolegend) and analyzed by flow cytometry [28]. For the AC infection model, each Sprague-Dawley rat and BALB/c mouse were orally infected with 100 and 30 AC larvae (L3), respectively. AC larvae (L3) were collected from the tissue of infected Biomphalaria glabrata as previously described [29]. The mice and Sprague-Dawley rats were euthanized on days $7,14,21$, and 28 after infection with AC.

\section{Histological examination and immunohistochemistry}

Brain and lung hematoxylin and eosin staining and immunofluorescence were performed on 5-mm-thick, $4 \%$ paraformaldehyde-fixed, paraffin-embedded slices. Antibodies against mouse Ym1 (60130, StemCell Technologies), CD11b (MAB1124, R\&D Systems), and Iba1 (NCNP24, Wako) were used as primary antibodies, with the corresponding secondary antibodies labeled with FITC or Alexa Fluor ${ }^{\circledR}$ 594. In addition, nuclei of cells were displayed by DAPI staining. All tissue slices 
were examined with laser-scanning confocal microscopy (Zeiss LSM780; Germany).

\section{Flow cytometry analysis}

Flow cytometry analysis was performed on a CytoFLEX $\mathrm{S}$ flow cytometer (Beckman Coulter).

For blood and brain macrophage and eosinophil assessment, PBMCs and BMNCs were isolated as previously described [25] and then incubated with Siglec F PE (BD), CD11c PE-Cyanine5 (eBioscience), or CD11b APC-cy7 (eBioscience) at $4{ }^{\circ} \mathrm{C}$ for $30 \mathrm{~min}$.

To determine the cell sources of Chi3l3, BMNCs were stained with CD11b PE (eBioscience), F4/80 PE-Cyanine5 (eBioscience), CD45 PE-eFluor 610 (eBioscience), Ly-6C PerCP/Cy5.5 (Biolegend), CX3CR1 Alexa Fluor 488 (eBioscience), or CCR2 Phycoerythrin (R\&D) at $4{ }^{\circ} \mathrm{C}$ for $30 \mathrm{~min}$.

For measurement of IL-5 and IL-13 levels, spleen cells [30] from normal and AC-infected mice were incubated with CD3 APC (eBioscience), CD4 FITC (eBioscience), and IL-13 PE cy7 (eBioscience) at $4{ }^{\circ} \mathrm{C}$ for $30 \mathrm{~min}$ and analyzed by flow cytometry.

To determine the possible effects of Chi3l3 and sAg on IL-13 production, spleen cells isolated from normal and AC-infected mice were cultured in 24-well cell culture plates for $72 \mathrm{~h}$, followed by a 12-h incubation with Brefeldin A and 6-h stimulation with PMA and ionomycin. Then, the cells were incubated with CD3 APC (eBioscience), CD4 FITC (eBioscience), or IL-13 PE cy7 (eBioscience) at $4{ }^{\circ} \mathrm{C}$ for $30 \mathrm{~min}$ and analyzed by flow cytometry.

\section{Cell metabolism measurement}

OCR (Oxygen Consumption Rate) and ECAR (Extracelluar Acidification Rate), as indicators of cellular oxidative phosphorylation and glycolysis, respectively, were monitored consecutively with a Seahorse Bioscience extracellular flux analyzer (XF24, Seahorse Bioscience) as described previously [31]. Approximately 15,000-25,000 cells were seeded in 24-well plates cultured with $500 \mu \mathrm{L}$ complete medium and incubated for $24 \mathrm{~h}$ in a $37{ }^{\circ} \mathrm{C}$ incubator. Then, cells were immersed in $500 \mu \mathrm{L}$ specified medium following two wash steps with specified medium and incubated in an incubator without $\mathrm{CO}_{2}$ for $1 \mathrm{~h}$ before the measurements.

The basal levels of OCR were recorded thrice as were the OCR levels after sequential addition of $1 \mu \mathrm{M}$ oligomycin, $1.0 \mu \mathrm{M}$ FCCP, and $0.5 \mu \mathrm{M}$ rotenone $+0.5 \mu \mathrm{M}$ antimycin A. Similarly, ECAR was measured under basal conditions and after the injection of the following drugs: $10 \mathrm{mM}$ glucose, $1.0 \mu \mathrm{M}$ oligomycin, and $50 \mathrm{mM}$ 2-deoxyglucose (2-DG).

\section{Protein and mRNA analysis}

Mouse and rat brains were dissected into the cerebrum and cerebellum and stored in TRIzol at $-80{ }^{\circ} \mathrm{C}$. Total RNA was extracted using TRIzol (Life Technologies) reagent and reverse-transcribed to cDNA using a RevertAid $^{\text {tw }}$ FirstStrand cDNA Synthesis Kit (Thermo Fisher Scientific, USA) according to the manufacturer's protocol. Specific gene expression was quantified with SYBR $^{\circ}$ Premix Ex Taq ${ }^{\text {Tix }}$ (Tli RNaseH Plus) (RR420A) using the Roche LightCycler 480 real-time PCR platform.

The following amplification primers (Sangon Biotech) were used ( $5^{\prime}$ to $3^{\prime}$ ): mouse Chi3l3 (sense, CTGAATGAA GGAGCCACTGA; antisense, AGCCACTGAGCCTTCA ACTT), mouse $\beta$-actin (sense, GGCATCCTGACCCTGA AGTA; antisense, CTCTCAGCTGTGGTGGTGAA), rat Chi3l3 (sense, AGTACCCTATGCCGTTCAGG; antisense, CAGACCATTGCACCTCCTAA), rat B2m (sense, GTCACCTGGGACCGAGAC; antisense, GAAGATGGT GTGCTCATTGC), and rat Hprt1 (sense, CTGTCATGT CGACCCTCAGT; antisense, GTCCATAATCAGTCCAT GAGGA).

The cerebrums and cerebellums of mice and rats were lysed using RIPA Lysis Buffer (Strong) (Cwbiotech), followed by SDS-PAGE. After transfer to nitrocellulose membranes (GE Healthcare) using the Semi-Dry Transfer with Trans-Blot ${ }^{\circ}$ SD Semi-Dry Transfer Cell (Bio-Rad), target proteins were verified with the corresponding antibodies. The following primary antibodies were used: mouse JMJD3 (ab85392, Abcam), CREB1 (A11989, ABclonal), CEBPB (A0711, ABclonal), KLF4 (A11853, ABclonal), Y641 phosphorylated-STAT6 (ab54461, Abcam), STAT6 (5397, Cell Signaling Technology), Chi3l3 (\#60130, STEMCELL Technology), PPAR $(81 \mathrm{~B} 8$, Cell Signaling Technology), and $\beta$-actin (12262, Cell Signaling Technology).

\section{RNA-seq data collection and processing}

Our group generated RNA-seq data of AC infection in mouse brain tissue [32]. The raw data were processed using a standard pipeline as follows: we first filtered the low-quality tags and trimmed adaptors. Next, we applied TopHat to map the clean reads to the Mus musculus 9 genome; we then used cufflinks and Cuffdiff to calculate the expression levels of transcripts and to analyze the differential expression, respectively.

\section{An algorithm for selecting marker genes from dynamic gene expression data Selection of TCGs (significantly changing genes)}

The RNA-seq data were measured on the 2nd, 7th, 14th, and 21st day post-infection. As gene expression temporally changed over time, we selected significantly changing genes by calculating the fold change of each gene between any two time points. For a given gene $G_{i}$ 
at time points $t_{j}(j=1,2, \ldots, 5)$, if the following criteria were satisfied, then it was defined as a significant TCG:

(a) $\max _{k}\left(G_{i}\left(t_{k}\right)\right) \geq \theta$;

(b) $G_{i}\left(t_{j}\right) / G_{i}\left(t_{k}\right) \geq \delta_{1}$ or $G_{i}\left(t_{j}\right) / G_{i}\left(t_{k}\right) \leq 1 / \delta_{1}$.

That is, a given gene was defined as a TCG if the maximal expression level of this gene is greater than $\theta$ and the fold change of its expression level between two time points is greater than $\delta_{1}$. In this study, $\theta$ was set to 10 , and $\delta_{1}$ was set to 5 .

\section{Clustering of expression patterns of TCGs}

We performed an unsupervised hierarchical clustering of the expression levels of TCGs using the R package "hclust." Then, the cluster tree was divided into six groups, and the gene expression pattern of each cluster was plotted.

\section{Ranking of significantly changing genes}

We ranked the significantly changing genes in the selected clusters (for example, sustained increasing or decreasing clusters) based on their changing rates at each time point. The changing rate of gene expression was defined as follows:

$$
R_{i}\left(t_{k}\right)=\frac{G_{i}\left(t_{k+1}\right)-G_{i}\left(t_{k}\right)}{t_{k+1}-t_{k}}
$$

where $G_{i}\left(t_{k}\right)$ is the normalized expression level of gene $i$ at time point $t_{k}$. Then, the genes were ranked according to the maximal absolute value of their changing rates at all time points.

\section{Functional protein association networks and functional enrichment analysis}

The functional protein association network for the genes in each cluster was constructed using the STRING database (https://string-db.org/). In this study, a medium confidence level (0.4) was selected to construct the network. We investigated the enriched functions of genes in the constructed network by performing functional enrichment using the DAVID webserver (https://david.ncif crf.gov/). The adjusted $P$ values were examined to select the significantly enriched biological processes.

\section{Mathematical model for Chi3/3-IL-13 positive feedback} We built a mathematical model to describe the dynamics of expression levels of Chi3l3 and IL-13 using ODEs as follows:

$$
\frac{d[\text { Chi3l3 }]}{d t}=a+\frac{V_{1} \cdot[I L 13]^{n_{1}}}{K_{1}^{n_{1}}+[I L 13]^{n_{1}}}-d_{1} \cdot[\text { Chi3l3 }]
$$

$$
\frac{d[I L 13]}{d t}=b+\frac{V_{2} \cdot[\text { Chi3l3 }]^{n_{2}}}{K_{2}{ }^{n_{2}}+[\text { Chi3l3 }]^{n_{2}}}-d_{2} \cdot[\text { IL13] }
$$

where [Chi3l3] and [IL13] represent the normalized expression levels of Chi3l3 and IL-13, respectively. $a$ and $b$ are the basic transcript rates of Chi3l3 and IL-13. $V_{1}$ is the maximal activation rates of Chi3l3 promoted by IL-13, and $V_{2}$ is that of IL-13 promoted by Chi3l3. $K_{1}$ and $K_{2}$ are the Michealis constants. $n_{1}$ and $n_{2}$ are Hill coefficients. $d_{1}$ and $d_{2}$ are degradation rates of Chi3l3 and IL-13, respectively.

The above ODEs were numerically solved using the 4th order Runge-Kutta method. The parameters in the above model was estimated using the non-linear least square method by fitting the model simulation to the experimental data. The experimental data were resampled using the 3rd order Hermite polynomial interpolation scheme. The genetic algorithm [33, 34] was employed to optimize the objective function. The estimated parameter values are as follows: $V_{1}=0.2588$, $V_{2}=0.9686, K_{1}=0.6980, K_{2}=0.5216, n_{1}=2, n_{1}=1, d_{1}$ $=0.1216, d_{2}=0.4824, a=0.0039$, and $b=0.0235$. The programming was performed in MATLAB R2007b (MathWorks, USA). The bifurcation analysis was performed using Oscill8 (http://oscill8.sourceforge.net).

\section{Results}

Chi3l3 in mouse brains increased sharply during AC-induced eosinophilic meningitis

AC induced serious eosinophilic meningitis or meningoencephalitis when mice were infected with the thirdstage larvae $(L 3)$ of AC. To elucidate the underlying mechanism of eosinophil infiltration in the brain, we analyzed the dynamic gene expression profiles of mouse brains using RNA-seq data [32]. We designed an algorithm for selecting significant temporally changing genes (TCGs), and 336 genes were identified as TCGs. The expression profiles of these TCGs are shown in a heatmap (Fig. 1a). TCGs were then clustered into six groups (Fig. 1b); each group had a different dynamic expression pattern. The cluster 1 genes showed a sustained increasing expression pattern after AC infection, indicating possible important functions. Therefore, we then analyzed the dynamic properties of cluster 1 genes by calculating their changing rates as defined in Eq. (1) in the "Methods" section. The maximal values of the changing rates of these genes at all time points were calculated and ranked from the largest to the smallest. We confirmed LOC547349 and Chi3l3 as the top two genes (Table 1), and Chi3l3 showed higher expression than LOC547349 (Additional file 1: Figure S1). Therefore, we hypothesized that Chi3l3 was an important molecule in $\mathrm{AC}$ infection. We further investigated the differences in Chi3l3 expression between non- 


\section{a}

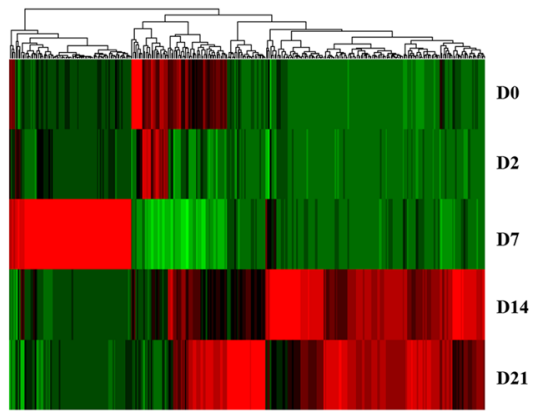

b

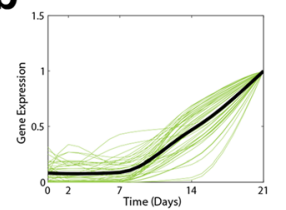

Cluster 4

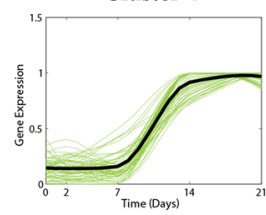

e
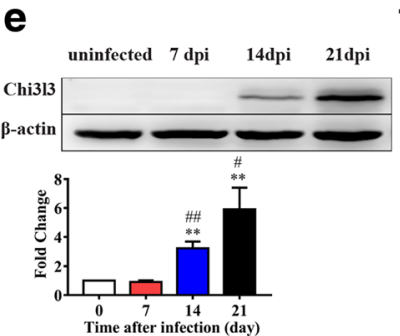

Cluster 2

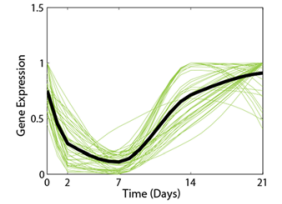

Cluster 5

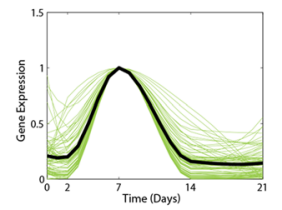

f c 呇
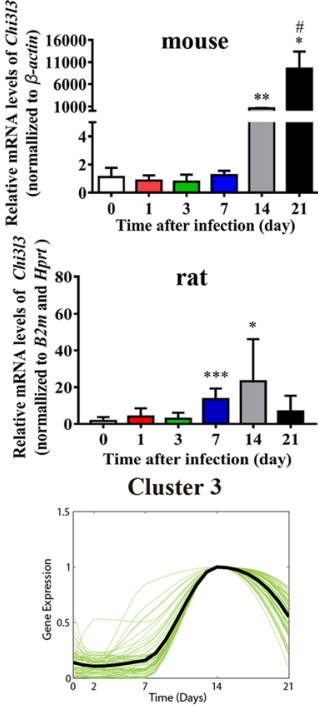

Cluster 6

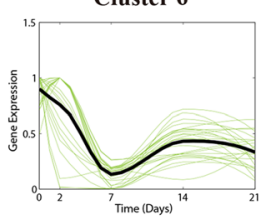

\begin{tabular}{|l|r|}
\hline Ctbs & 5 \\
\hline Chia & 4 \\
& 2 \\
\hline Chi314 & 1 \\
\hline & 0 \\
\hline Ovgp1 & -1 \\
\hline Chit1 & -2 \\
\hline Chi313 \\
\hline Chi311 \\
\hline
\end{tabular}

Fig. 1 Elevation of Chi3/3 expression in the brain is an important characteristic in non-permissive host mice but not in permissive host rats during AC infection. a Expression profile of significant TCGs after AC infection. The horizontal axis represents genes, and vertical coordinates represents time points. D0 is the normal control group. D2, D7, D14, and D21 represent 2, 7, 14, and 21 dpi, respectively. $\mathbf{b}$ Expression patterns of TCGs. The $x$-axis represents time (with the unit as day), and the $y$-axis represents the normalized gene expression levels. $\mathbf{c}$ The mRNA levels of Chi3/3 in brains of mice infected with AC at 0 , $1,3,7,14$, and 21 dpi. Mouse $\beta$-actin mRNA was used as an internal control. ${ }^{*} P<0.05$. infected groups vs control group; ${ }^{\#} P<0.01,14$ dpi group vs 21 dpi group. $\mathbf{d}$ The mRNA levels of Chi3l3 in brains of rats infected with $A C$ at $0,1,3,7,14$, and 21 dpi. Rat B2m and Hprt1 mRNA levels were used as internal controls. ${ }^{*} P<0.05$, ${ }^{*} P<0.01$, infected groups vs control group. $\mathbf{e}$ The protein levels of Chi3l3 in brains of mice infected with $A C$ at $0,7,14,21$, and $28 \mathrm{dpi}$. $\beta$-Actin was used as an internal control. ${ }^{*} P<0.05,{ }^{* *} P<0.01,{ }^{* * *} P<0.001$, infected groups vs uninfected groups in the corresponding part. $\mathbf{f} A$ gene set enrichment analysis of transcriptome data was performed by comparing the mRNA levels of CLPs and chitinases in brains of mice infected with AC at 0,2 , 7, 14, and 21 dpi. Data information: In $\mathbf{c}-\mathbf{e}$, data are presented as mean \pm SD. (Student's $t$ test)

permissive hosts (mice) and permissive hosts (rats) infected with $\mathrm{AC}$ and were surprised to find that the mRNA and protein levels of Chi3l3 in the brain varied greatly between mice and rats during infection (Fig. 1c, d). Mouse brain Chi3l3 mRNA levels increased from 1000 at $14 \mathrm{dpi}$ to 10,000 at $21 \mathrm{dpi}$ (Fig. 1d), and the protein level experienced a fold increase from $14 \mathrm{dpi}$ to $21 \mathrm{dpi}$ (Fig. 1e). Notably, AC infection time-dependently upregulated chitinases and chitinase-like proteins (CLPs) at $0,2,7,14$, and $21 \mathrm{dpi}$, with Chi3l3 being the most significant one (Fig. 1f), in accordance with our gene microarray data [35].
Collectively, these results indicated that a sharp increase of Chi3l3 was observed in non-permissive host mice but not in permissive host rats during $\mathrm{AC}$ infection, and thus, Chi3l3 is likely to be an important element closely correlated with eosinophilic meningitis [24, 25, 35].

\section{Eosinophil percentage is coordinated with $\mathrm{Chi} 3 \mathrm{I} 3$ derived} from inflammatory macrophages in brains of AC-infected mice

Excess Chi3l3 in the brain prompted us to investigate the possible cell source of this molecule. Flow cytometric analysis revealed that approximately $8 \%$ of brain 
Table 1 Top 10 genes ranked according to the maximal changing rate of genes in cluster 1 of gene expression patterns

\begin{tabular}{lll}
\hline Gene symbols & Maximal changing rate & Maximal expression level \\
\hline LOC547349 & 0.139800 & 22.7645 \\
Chi3l3 & 0.136786 & 210.624 \\
Aqp1 & 0.126326 & 12.3571 \\
Apoc4 & 0.119975 & 12.3525 \\
Mmp3 & 0.11429 & 10.435 \\
Retnla & 0.113539 & 1140.52 \\
Ccl4 & 0.101572 & 34.1275 \\
Ch25h & 0.097177 & 15.4714 \\
Serpina3h & 0.096369 & 20.2997 \\
S100a8 & 0.095943 & 127.981 \\
\hline
\end{tabular}

mononuclear cells (BMNCs) of mice infected with $\mathrm{AC}$ at 21 dpi were Chi3l3-positive $\left(\mathrm{Chi} 3 \mathrm{l}^{+}\right)$cells. Further analysis showed that the majority $(81.8 \%)$ of $\mathrm{Chi} 33^{+}$cells possess a $\mathrm{CD} 45^{\text {hi }} \mathrm{F} 4 / 80^{+} \mathrm{CD} 11 \mathrm{~b}^{+}$phenotype (Fig. 2a). Monocytes/macrophages are currently divided into two classes, "inflammatory" type $\left(C C R 2{ }^{+} L y-6 C^{\text {hi }}\right.$ CD62L ${ }^{+} \mathrm{CX} 3 \mathrm{CR} 1^{\text {lo }}$ ) and "resident" type (CCR2 ${ }^{-} \mathrm{Ly}-6 \mathrm{C}^{\mathrm{lo}} \mathrm{CD} 62 \mathrm{~L}$ ${ }^{-}$CX3CR1 ${ }^{\text {hi }}$ ) cells [36]. The above observation suggested that bone marrow-derived myeloid cells may be recruited to the inflamed CNS during AC infection, similar to other brain inflammatory diseases, such as multiple sclerosis and experimental autoimmune encephalomyelitis [37]. To test this hypothesis, we assessed CCR2, Ly-6C, and CX3CR1 as previously described [36]. Chi3l3 ${ }^{+}$BMNCs are primarily characterized by Ly- $6 \mathrm{C}^{+} \mathrm{CCR} 2$ ${ }^{+} \mathrm{CX} 3 \mathrm{CR} 1{ }^{\mathrm{lo}}$ and a low side scatter profile (Fig. $2 \mathrm{~b}$ ), which indicate an "inflammatory" subset of monocytes/macrophages, not a "resident" subset [36]. In addition, kinetics of $\mathrm{CD} 45^{+} \mathrm{F} 4 / 80^{+}$cell infiltration in the brain was evaluated; Chi3l ${ }^{+}$cells were first observed at $14 \mathrm{dpi}$, and the cell percentage increased sharply with eosinophilic meningitis progression (Fig. 2e), accompanied by enhanced expansion of $\mathrm{CD} 45^{\mathrm{hi}} \mathrm{F} 4 / 80^{+}$cells compared to $\mathrm{CD} 45^{\mathrm{lo}} \mathrm{F} 4 / 80^{+}$ cells (Fig. 2d). Further evaluation of the macrophagespecific markers Iba1 [38] and CD11b by immunofluorescence revealed that infiltrating cells were differentiated mature macrophages after AC infection (Fig. 2c).

Intriguingly, we found that the eosinophil percentage synchronized with Chi3l3 and IL-13 levels in brains of AC-infected mice, with a percentage of approximately $2 \%$ at $7 \mathrm{dpi}$. The eosinophil percentage rose sharply over time, exceeded $20 \%$ at $14 \mathrm{dpi}$, and finally reached $40 \%$ at $21 \mathrm{dpi}$ (Fig. 2e). In contrast to the CNS symptoms of AC-infected mice, we did not observe obvious changes in the eosinophil percentage in the blood of AC-infected mice at $14 \mathrm{dpi}$ and $21 \mathrm{dpi}$ compared with the uninfected healthy mouse group, although there was a slight increase in eosinophil percentage at $7 \mathrm{dpi}(P<0.05)($ Fig. $2 \mathrm{f})$.
To define the potential relationship between macrophage infiltration and eosinophilic meningitis in AC infection, we administered liposomal clodronate [39] prior to and during the infection to effectively deplete macrophages (Fig. 2g). As expected, treatment with liposomal clodronate (Fig. 2g) blocked the accumulation of macrophages in the brain after AC infection, decreased Chi3l3 (Fig. 2h), and relieved CNS pathology (Fig. 2i) at $22 \mathrm{dpi}$.

Soluble antigens of AC larvae (sAg) play an expanding role in eosinophilic response in an airway allergy mouse model A previous study showed that cellular infiltration around dead worms was more prominent than that around living ones [1], and these findings prompted us to investigate the function of $\mathrm{sAg}$ in eosinophil recruitment. Alternaria extract induces a pulmonary allergic reaction in mice, thus providing an ideal model for studies concerning the effect of helminths and their products on innate and adaptive immune responses [40, 41]. After 4 days of in vivo exposure to Alternaria and sAg, we observed an increase in eosinophils of bronchoalveolar lavage (BAL) fluid in C57BL/6 mice from the sAg administration group $2 \mathrm{~h}$ after Alternaria treatment (Fig. 3a, b).

These results demonstrate that the sAg stimulus may directly or indirectly affect the brain microenvironment during AC-induced eosinophilic meningitis.

\section{Network analysis and mathematical modeling predict a functional association between Chi3/3 and IL-13}

To investigate the possible interactions of Chi3l3 with other genes, we constructed a functional interaction network of Chi3l3. We first calculated the Pearson correlation coefficients of Chi3l3 with all the other genes. The genes that were highly correlated with Chi3l3 (correlation coefficient greater than 0.8) were identified and input into the STRING database (https://string-db.org/). In this study, a medium confidence level (0.4) was selected to construct a functional gene association network (Fig. 4a). Then, a subnetwork containing all genes interacting with Chi3l3 was extracted (Fig. 4b). IL-4, IL-13, and CCL2 were predicted to be functionally associated with Chi3l3.

The functional enrichment of genes in the Chi3l3 network was performed as shown in Fig. 4c. The significantly enriched biological processes include response to organic substance, response to stress, immune system process, response to chemical, regulation of response to stimulus, single-multicellular organism process, positive regulation of biological process, multicellular organismal process, regulation of localization, and regulation of immune system process.

Both RNA-seq data and qPCR measurements from in vivo experiments (Fig. 4d, e) indicated that Chi3l3 and IL13 showed a high positive correlation and burst expression pattern. Therefore, we hypothesized that a positive feedback 


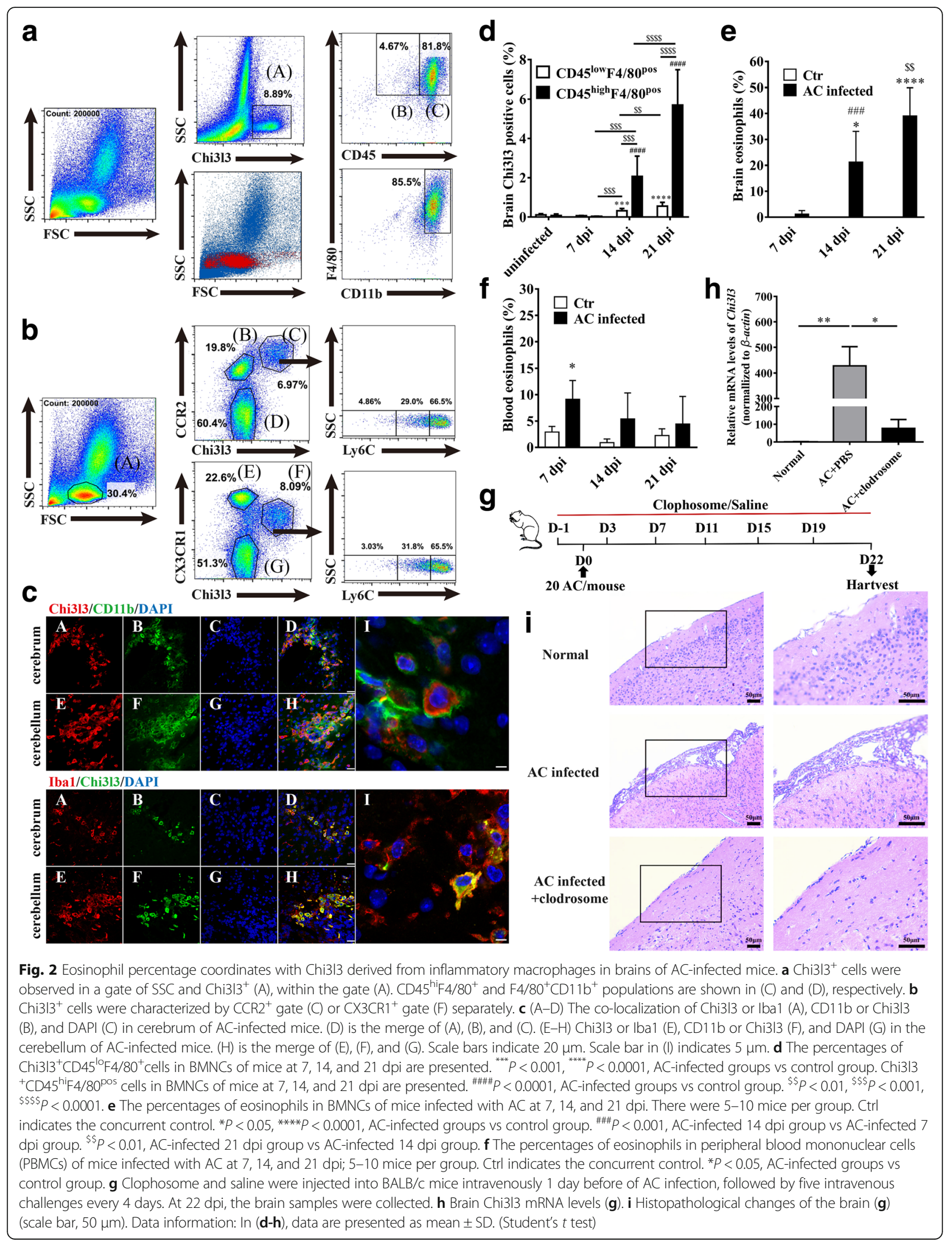




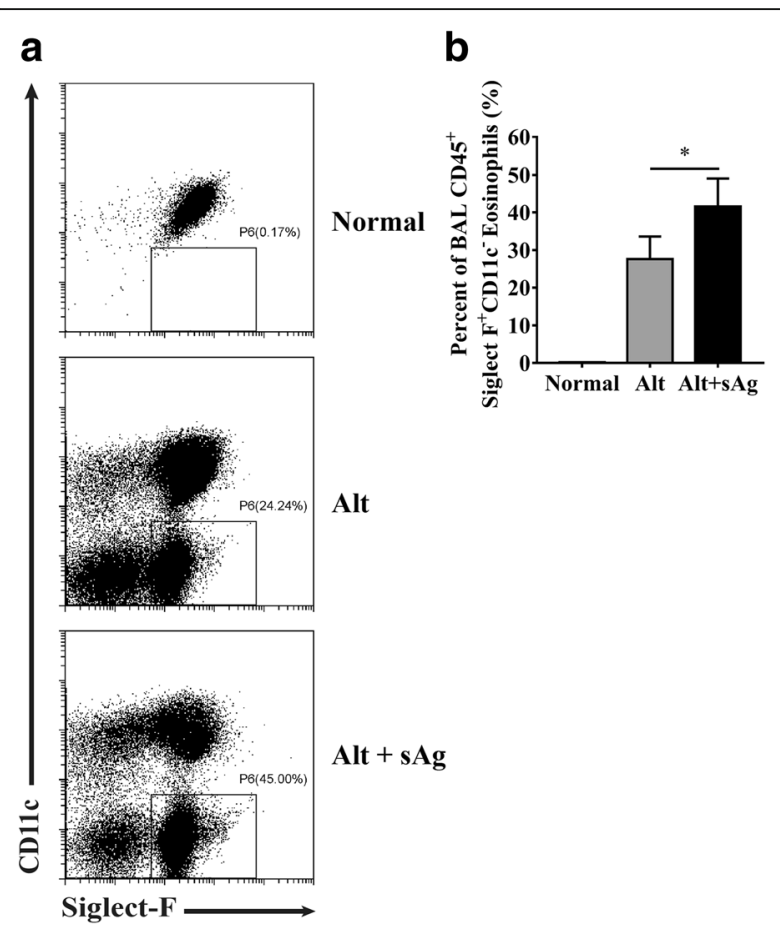

Fig. $3 \mathrm{sAg}$ aggravates eosinophilic response in an airway allergy C57BL/ 6 mouse model. a BAL eosinophil percentages were measured 4 days after daily administration of sAg $2 \mathrm{~h}$ before Alternaria exposure. $\mathbf{b}$ The results are representative or pooled from three repeat experiments, $3-5$ mice per group. ${ }^{*} P<0.05$. Data information: In $\mathbf{b}$, data are presented as mean \pm SD. (Student's $t$ test)

loop might exist between Chi3l3 and IL-13. To test this hypothesis, we developed an ordinary differential equation (ODE) model describing the positive feedback between Chi3l3 and IL-13 (Eqs. (2-3) in the "Methods" section] to quantitatively study the dynamics of Chi3l3 and IL-13 expression. We fitted the mode to the in vivo experimental data (Fig. 4d, e). A good agreement between the theoretical and experimental results (the mean squared error is 0.0849) supported the hypothesized positive feedback loop between Chi3l3 and IL-13. Moreover, bifurcation analysis of the model revealed a bistable switch of Chi3l3 and IL-13 with respect to the parameter $K_{2}$ (Fig. 4f). As the value of $K_{2}$ increased above $\sim 2.63$, the steady states of Chi3l3 and IL-13 then switched from high levels to low levels. The bistability of this system indicated the state transition of infection progression and heterogeneity of infection outcome between individuals. The switches induced by the increase in the value of $K_{2}$ suggested that therapeutically inhibiting the IL-13 signaling pathway, including the IL-13 receptor, might ameliorate the $\mathrm{AC}$ infection.

sAg aggravates the positive feedback loop between IL-13 and $\mathrm{Chi} 3 \mathrm{I} 3$

Flow cytometry analysis was carried out, which indicated IL-13 and IL-5 expression of $\mathrm{CD}^{+} \mathrm{CD}^{+}$lymphocytes
(Fig. 5a, b) in spleen, the most important peripheral immune organ. We observed a significant increase from 0.4 to $0.6 \%$ in $\mathrm{IL}-13^{+}$expression of spleen-derived $\mathrm{CD}^{+} \mathrm{CD} 4^{+}$ cells, but not IL-5, which is consistent with the qPCR results of brains (Fig. 4e) (Additional file 2: Figure S2e).

To clarify whether Chi3l3 acts as a positive regulator of IL-13 cytokine production in our model, we cultured splenocytes of normal or AC-infected mice for $72 \mathrm{~h}$ in the presence of sAg or Chi3l3 followed by a 6-h PMA and ionomycin stimulation to increase cytokine production (Fig. 5c, d). We found that Chi3l3 enhanced spleen $\mathrm{CD}^{+}{ }^{+} \mathrm{CD}^{+}{ }^{+} \mathrm{T}$ cell IL-13 secretion, with a percentage increase from 0.8 to $1.5 \%$ (Fig. 5 c) and 0.8 to $1.9 \%$ (Fig. $5 \mathrm{~d}$ ) in normal mice and AC-infected mouse spleens, respectively.

Consistent with our previous study using RAW 264.7 cells [25], we found that BMDM Chi3l3 initiated by IL-13 was also promoted by sAg (Additional file 2: Figure S2a) (Fig. 5e). Thus, we hypothesized that uncontrolled Chi3l3 is achieved by an interlaced net of signaling pathways and transcription factors vital to the alternative activation of macrophages, including STAT6 phosphorylation [42], Histone H3 modification [43], PPAR [44], C/EBP $\beta$ [45], and KLF4 [46] activation. We found that only BMDM PPARY expression (Additional file 2: Figure S2b) (Fig. 5e) increased when stimulated with IL-13 and sAg plus IL-13, and sAg and IL-13 co-stimulation further enhanced Chi3l3. These data indicate that PPAR $\gamma$ is a strong activator of BMDM Chi3l3 expression in the sAg and IL-13 co-stimulation model. PPAR $\gamma$ is a known director of the oxidative phosphorylation process, which regulates M2 activation by controlling gene expression critical for metabolic reprogramming [44]. To gain insight into the metabolism of BMDMs in modulation of Chi3l3 expression, we measured the basal OCR, max OCR, and SRC OCR (spare respiratory capacity; the difference between basal OCR and max OCR) [31] level of BMDMs (Fig. 5g-i). Consistent with the increase in PPAR $\gamma$, elevated OCR indicated that BMDMs displayed an enhanced oxidative phosphorylation metabolic phenotype (Fig. 5f).

Based on the results above, we verified the skewed cytokine pattern in brains of AC-infected mice, especially Chi3l3, which may be due to the positive feedback loop between IL-13 and Chi3l3 of inflammatory macrophages. This may be mediated by activating the PPAR $\gamma$ signaling pathway, which is associated with oxidative phosphorylation.

\section{Discussion}

Previous studies have identified alternative activated macrophages as a hallmark of various parasitic diseases, including filarial nematode Brugia malayi [10], Nippostrongylus brasiliensis [11], Trichinella spiralis [12], 


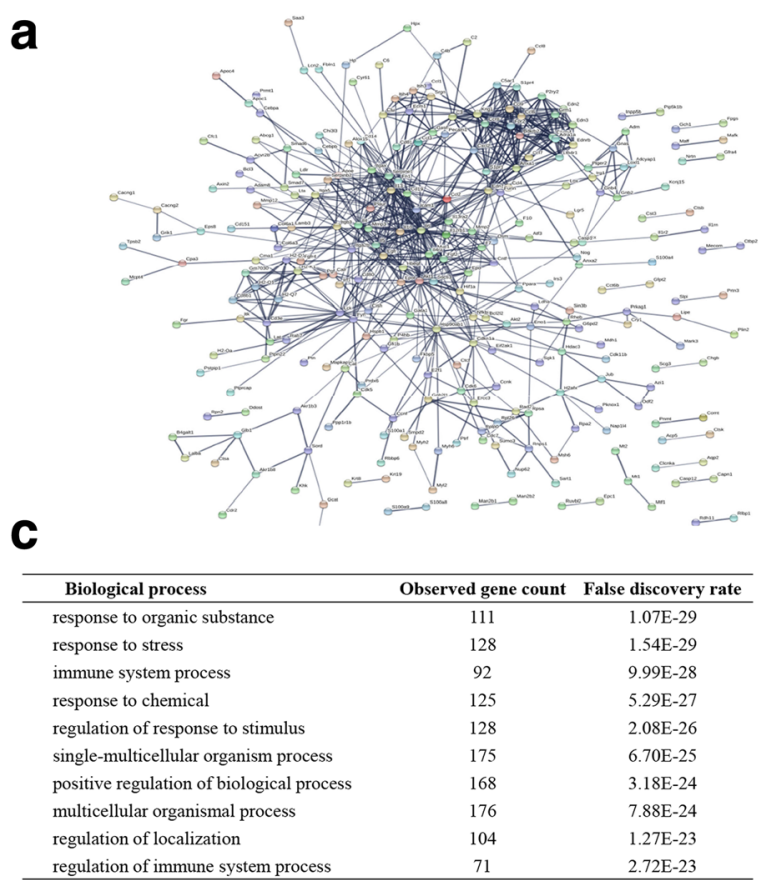

b
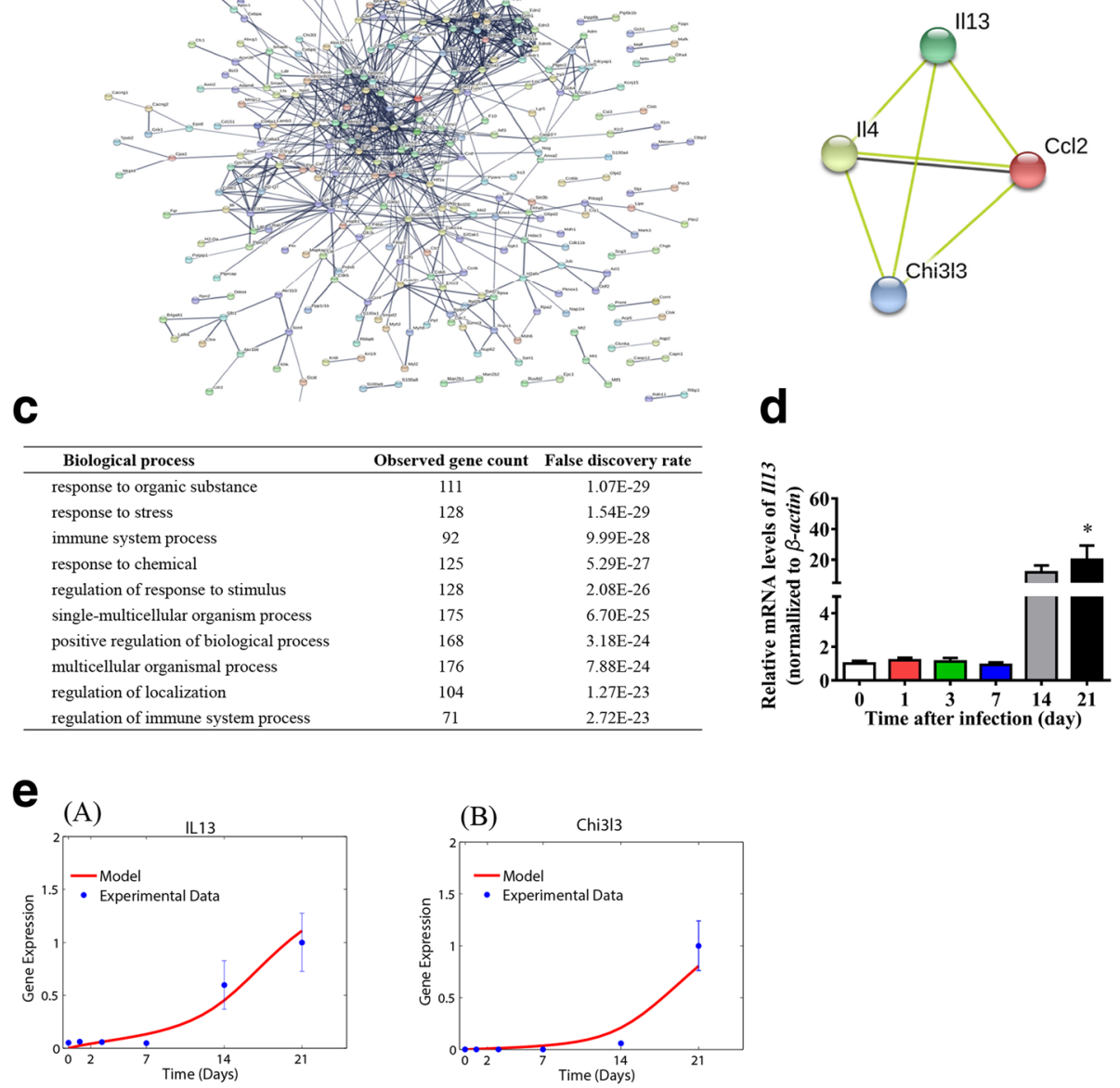

(C) IL13
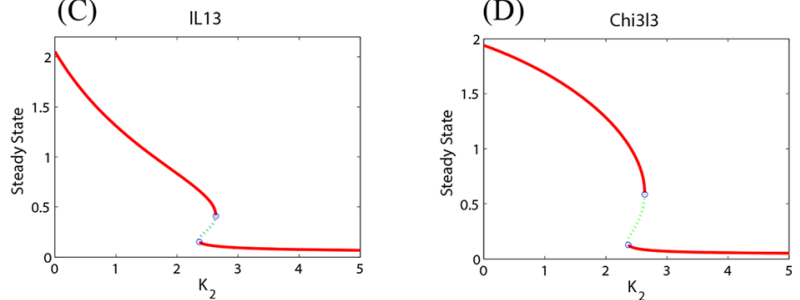

Fig. 4 Functional protein association networks for the genes correlated with Chi3l3. a A full view of the protein association network for the genes highly correlated with Chi3|3. b The sub-network specifically centered on Chi3|3. c Functional enrichment for the genes in cluster 1 of gene expression patterns. The top 10 biological processes with the observed gene count as well as the false discovery rate are listed. $\mathbf{d} \| \mathrm{L}-13 \mathrm{mRNA}$ levels in normal and AC-infected mouse brains. ${ }^{*} P<0.05$, AC-infected 21 dpi group vs control group. e A mathematical model for Chi313-IL-13 positive feedback and bifurcation analysis. (A, B) Fitting the model to the experimental data. (C, D) Bistability of Chi3I3 and IL-13 with respect to the parameter value ( $\left.K_{2}\right)$. Data information: In (d-e), data are presented as mean \pm SD. (Student's $t$ test)

Schistosoma japonicum [13], and Heligmosomoides polygyrus [14], along with high expression of Chi3l3 and major eosinophilic infiltration. The brain inflammation of AC-infected mice was characterized by major infiltration of eosinophils and "inflammatory" macrophages $\left(\mathrm{Ly}-6 \mathrm{C}^{+} \mathrm{CCR} 2^{+} \mathrm{CX} 3 \mathrm{CR} 1^{\mathrm{lo}}\right)$ and a sharp increase in brain Chi3l3, an eosinophilic chemotactic factor also known as Chi313, ECF-L or Ym1. It is induced by allergens and helminths and was shown to exert chemotactic activity for eosinophils [47]. According to our previous work on AC-infected mice, Chi3l3 is one of the most highly expressed molecules in the brain, much greater than traditional chemotactic factors associated with eosinophils, such as Eotaxin, IL-5, and IL-13 [15, 17-19]. Moreover, it appears to be preferentially expressed in the brain compared to other organs, strongly indicating a close relationship between Chi3l3 and eosinophilic meningitis [35]. 
a

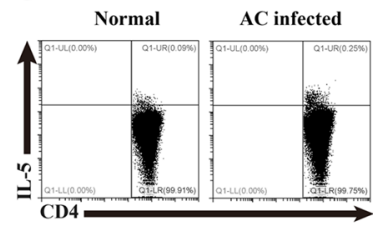

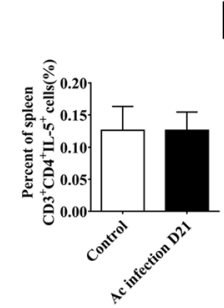

b
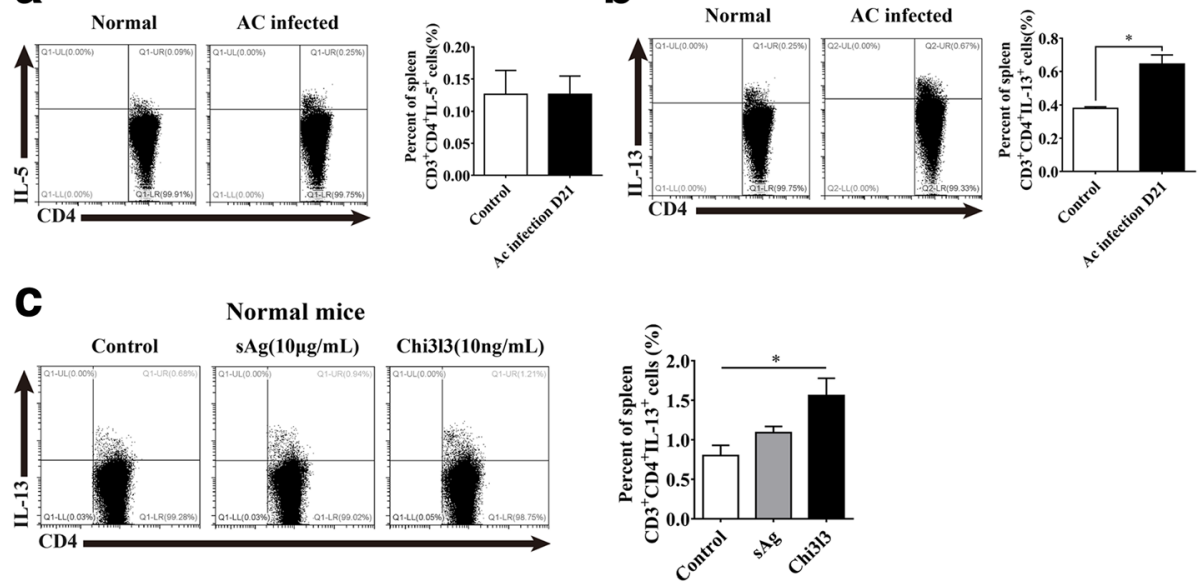

d

AC infected mice
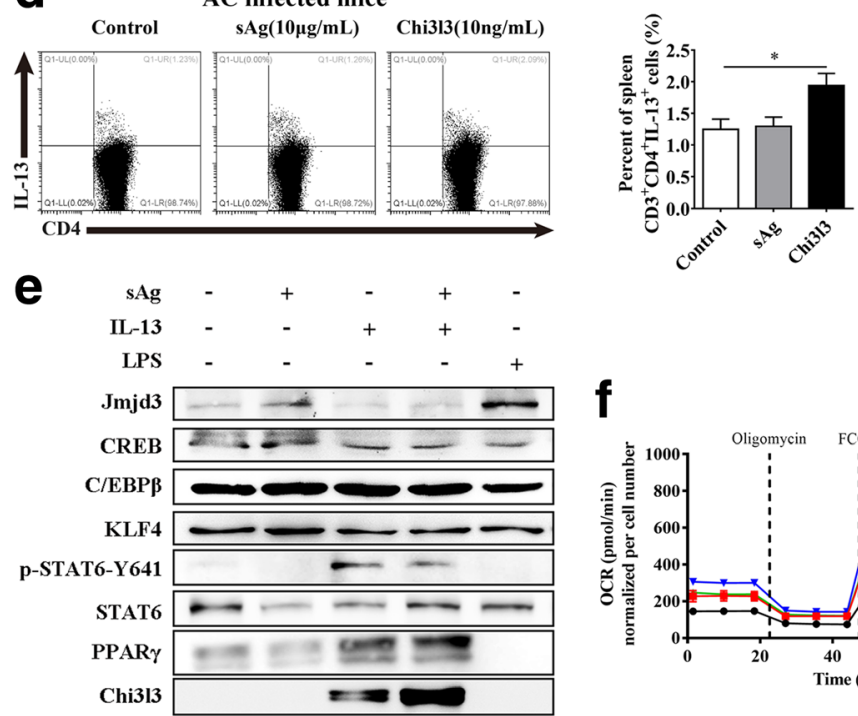

\section{g}

h
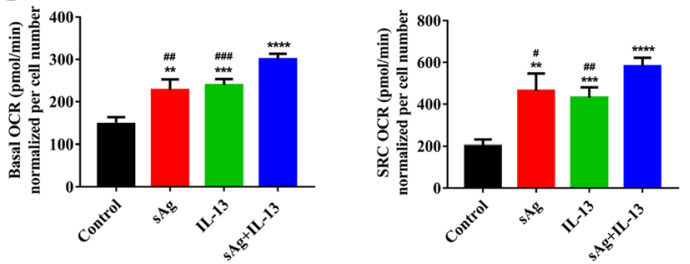

i

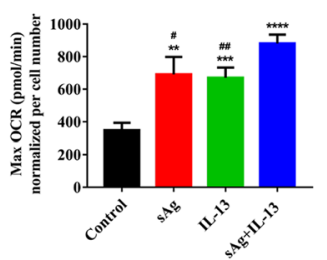

Fig. 5 A positive feedback loop between Chi3l3 from macrophages and IL-13 from T lymphocytes in vitro. a The percent of IL-5 $5^{+}$cells in $C D 3^{+} C D 4^{+}$spleen cells were detected by flow cytometry. $\mathbf{b}$ The percent of $\mathrm{IL}-13^{+}$cells in $\mathrm{CD}^{+}{ }^{+} \mathrm{CD} 4^{+}$cells. ${ }^{*} P<0.05$, AC-infected D21 (21 dpi) group vs control group. $\mathbf{c}$, d Spleen cells isolated from normal mice and AC-infected mice were stimulated with sAg $(25 \mu \mathrm{g} / \mathrm{mL})$ or Chi3l3 $(10 \mathrm{ng} / \mathrm{mL})$ for $72 \mathrm{~h}$ in vitro. A summary of the percentages of $1 \mathrm{~L}-13^{+} \mathrm{CD}^{+} \mathrm{CD}^{+}$cells following stimulation with $\mathrm{sAg}$ and Chi3/3 in normal mice. ${ }^{*} P<0.05$, Chi3l3 group vs control group. e Western blot analysis of Chi313, JMJD3, CREB1, CEBPB, KLF4, Y641 phospho-STAT6, STAT6, and PPARY of BMDMs in the presence of sAg, IL-13, sAg+IL-13, and LPS for 24 h. f Cells were cultured for $24 \mathrm{~h}$ in medium alone or treated with sAg, IL-13, or SAg+IL-13, and then, the OCR was monitored using the Seahorse Bioscience extracellular flux analyzer in real time. Dotted lines indicate incubation of cells with the indicated compounds. $\mathbf{g}$ Basal OCR of BMDMs cultured for $24 \mathrm{~h}$ in medium alone or treated with sAg, IL-13, or sAg+IL-13. ${ }^{* *} P<0.01,{ }^{* * *} P<0.001,{ }^{* * * *} P<0.0001$, sAg group, IL-13 group, sAg+IL-13 group vs control group. $P$

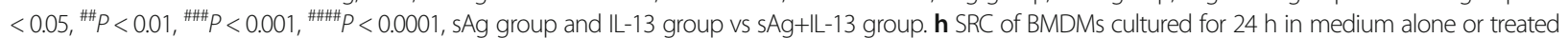
with sAg, IL-13, or sAg+IL-13. ${ }^{* *} P<0.01,{ }^{* *} P<0.001,{ }^{* * *} P<0.0001$, sAg group, IL-13 group, sAg+IL-13 group vs control group. ${ }^{\#} P<0.05,{ }^{\# \#} P<0.01$,

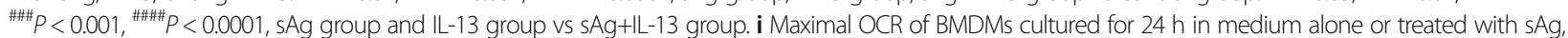
IL-13, or SAg+IL-13. ${ }^{* *} P<0.01,{ }^{* * *} P<0.001,{ }^{* * * *} P<0.0001$, sAg group, IL-13 group, $\mathrm{SAg}+\mathrm{IL}-13$ group vs control group. ${ }^{\#} P<0.05,{ }^{\# \#} P<0.01,{ }^{\# \# \#} P<0.001$, \#\#\#\# $P<0.0001$, sAg group and IL-13 group vs SAg+IL-13 group. Data information: In (a- $\mathbf{d}, \mathbf{f}-\mathbf{h})$, data are presented as mean \pm SD (Student's $t$ test) 
In this study, we first discovered an entirely different brain Chi3l3 expression pattern in permissive host rats compared to non-permissive host mice after AC infection. Interestingly, the dramatic increase of Chi3l 3 was a unique feature of the non-permissive host mice. Chi3l3 appeared to be a major causative factor of the symptoms, as "inflammatory" macrophages were the major source of this molecule, and depletion of macrophages led to downregulation of $\mathrm{Chi3l3}$ and relieved the brain symptoms of AC-infected mice. These findings are consistent with our previous results, which showed that Chi3l3 administration via the caudal vein resulted in a significant reduction in worm burden and augmented Chi3l3 protein levels in AC-infected mouse brains at 14 dpi compared with those of the saline administration AC-infected group [25]. Thus, continuous decomposition of worms is one reason for the rapid progression towards severity of this disease.

During the course of many helminth infections, M2 macrophages gradually accumulate in the lesion location, characterized by an increase of Chi3l3 [48], and both M2 macrophages and Chi3l3 may act as vital drivers of eosinophil recruitment in a Th2 cell-dependent manner [49], increasing severity of the lesions. Th2 cells are known to be critical sources of IL-4 and IL-13 [50], which are triggers of macrophage alternative activation.

Here, we selected IL-13 for further investigation of its function in AC infection and as a continuation of our previous study [25]. However, IL-4 and IL-13 share a signaling pathway (IL-4R $\alpha / \mathrm{IL}-13 \mathrm{R} \alpha 1 / \mathrm{STAT} 6)$ and similar functions [51]; thus, further research is needed to clarify the function of IL-4 in AC infection.

According to the mathematical analysis of our RNAseq data, the dysregulated brain Chi3l3 in our ACinfected mice appeared to be strongly correlated with the IL-13 level. Through a series of in vitro experiments, we confirmed that sAg switched the active and metabolic status of macrophages to a M2 phenotype and substantially promoted Chi3l 3 secretion via IL-13 in a PPAR- $\gamma$-dependent manner, suggesting that some helminth-derived molecules could be previously unknown sources of M2 activators. In turn, M2 macrophages enhanced Th2 polarization of spleen $\mathrm{T}$ lymphocytes through Chi3l3, forming a positive feedback loop, which may help explain the excess levels of Chi3l3 and IL-13 as well as the severe eosinophilic meningitis in the brain. As sAg aggravated the positive feedback loop between IL-13 and Chi3l3, breaking the loop between Chi3l3 and IL-13 is a promising treatment strategy for angiostrongyliasis.

Recent studies have shed light on the pharmacodynamic effects of helminth-derived molecules. Trichinella spiralis excretory/secretory (ES) antigens, as well as its recombinant protein $\mathrm{r} T s \mathrm{P} 53$, were reported to influence

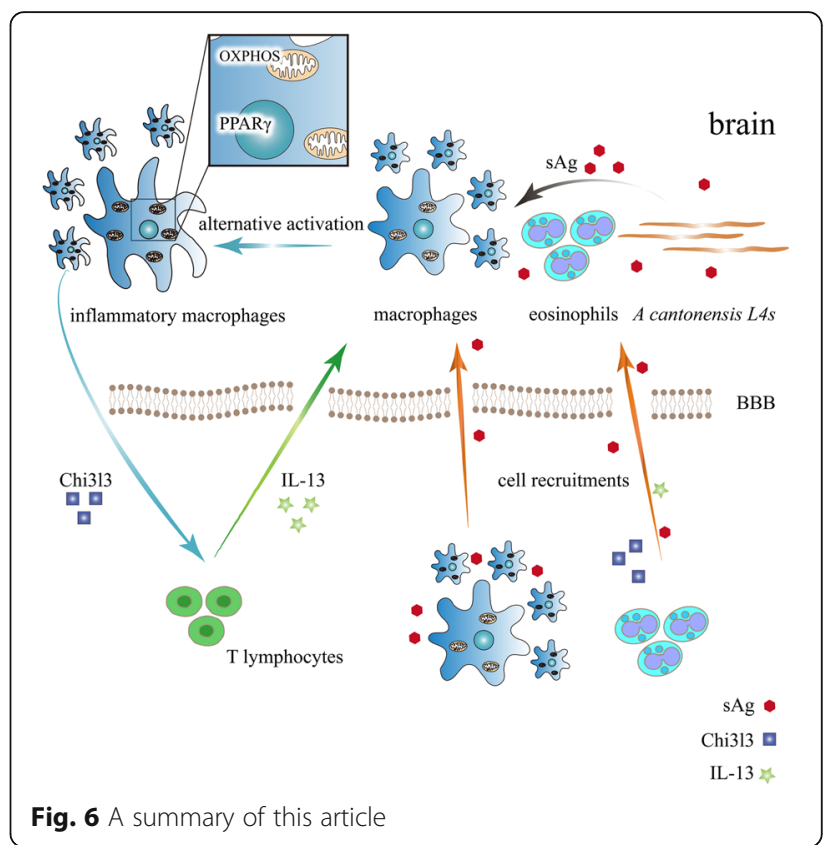

inflammatory cytokine production and the activation status of macrophages [12]. A Brugia malayi active cytokine mimic Bm-MIF-1 (macrophage migration inhibitory factor) was reported to induce Chi3l3 transcription in macrophages [52]. ES products from L3 larvae of Nippostrongylus brasiliensis can inhibit gene transcription of important inflammatory mediators in rat BAL cells. Filarial nematode-derived phosphorylcholinecontaining glycoprotein ES-62, as well as its phosphorylcholine-based small molecule analogues, may have applications in the treatment of rheumatoid arthritis [53, 54], chronic asthma [55], lupus erythematosus [56], and atherosclerosis [57] in mouse models. Trichuris suis-derived glycan [58] and Schistosoma japonicum-derived sj16 [59] provided protection against ulcerative colitis and DSS-induced colitis, respectively. We hypothesized that further component analysis of the active ingredients of sAg might contribute to drug development and vaccine design for parasitic or autoimmune diseases.

\section{Conclusions}

We present evidences in favor of a key role for macrophage-derived Chi3l3 molecule in the infection of Angiostrongylus cantonensis, which aggravates eosinophilic meningitis induced by Angiostrongylus cantonensis via a IL-13-mediated positive feedback loop (Fig. 6). The results above indicate a great value for further research of angiostrongyliasis pathogenesis and implied that targeting chitinases and chitinase-like-proteins may be clinically beneficial in Angiostrongylus cantonensis-induced eosinophilic meningitis. 


\section{Additional files}

Additional file 1: Figure S1. The comparison between the expression levels of the top two genes in Table 1. Chi313 and LOC547349 were ranked according to the maximal changing rate of genes in cluster 1 . Chi313 and LOC547349 have similar maximal changing rates, but Chi3l3 has a higher expression level. (TIFF $2791 \mathrm{~kb}$ )

Additional file 2: Figure S2. a-d. qPCR analysis of Chi3|3, PPARy, JMJD3, and KLF4 of BMDMs in the presence of $S A g, I L-13, s A g+\mid L-13$, and LPS for 24 h. E. IL-5 mRNA levels in normal and AC-infected mouse brains. ${ }^{*} P<0.05$ AC-infected 21 dpi group vs control group. (TIFF $739 \mathrm{~kb}$ )

\section{Abbreviations}

2-DG: 2-Deoxyglucose; AC: Angiostrongylus cantonensis/A. cantonensis; BAL: Bronchoalveolar lavage; BMDM: Bone marrow-derived macrophage; CLPS: Chitinase-like proteins; CNS: Central nervous system; dpi.: Days post infection; ECAR: Extracelluar Acidification Rate; OCR: Oxygen Consumption Rate; sAg: Soluble antigens of A. cantonensis larvae (L4); SRC: Spare respiratory capacity; TCGs: Significantly changing genes

\section{Acknowledgements}

Not applicable.

\section{Funding}

These experiments were supported by grants from Pearl River Nova Program of Guangzhou (Grant No. 201710010030), National Natural Science Foundation of China (Grant No. 81572014), the National High Technology Research and Development Program of China (Grant No. 2015AA020934), National Research and Development Plan of China (No. 2016YFC1200500), grant from the Doctoral Program of Higher Education of China (Grant No. 20120171120049), and grant from the National Science Foundation of Guangdong Province (Grant No. S2012040007256).

\section{Availability of data and materials}

All data used for the formulation of the conclusions in the manuscript are presented in the main paper.

\section{Authors' contributions}

SW, XQS, and FW performed the research. SW performed the q-PCR and flow cytometry. XQS performed the RNA-seq data analysis. FW performed the Western blotting, transmission electron microscopy staining and imaging. LFW, DTL, and ZYL analyzed the data. SW, XS, and ZDW designed the research, and SW and XQS wrote the article, with additional input from all authors. All authors read and approved the final manuscript.

\section{Ethics approval}

All the animal experiments were approved by the medical research ethics committee of Sun Yat-sen University and conformed to the Chinese National Institute of Health Guide for the Care and Use of Laboratory Animals (No. 2017-020)

\section{Consent for publication}

Not applicable

\section{Competing interests}

The authors declare that they have no competing interests.

\section{Publisher's Note}

Springer Nature remains neutral with regard to jurisdictional claims in published maps and institutional affiliations.

\section{Author details}

'Department of Parasitology of Zhongshan School of Medicine, Sun Yat-sen University, No.74 Zhongshan Road.2, Guangzhou, Guangdong 510080, China. ${ }^{2}$ Key Laboratory of Tropical Disease Control (SYSU), Ministry of Education, Guangzhou, Guangdong 510080, China. ${ }^{3}$ Provincial Engineering Technology Research Center for Biological Vector Control, Guangzhou, Guangdong 510080, China. ${ }^{4}$ Department of Clinical Laboratory, the Sixth Affiliated Hospital, Sun Yat-Sen University, Guangzhou, Guangdong 510080, China.
${ }^{5}$ Institute of Human Disease Genomics, Zhongshan School of Medicine, Sun Yat-Sen University, Guangzhou, Guangdong 510080, China. 'Department of neurology, The Second Affiliated Hospital of Nanchang University, Nanchang, Jiangxi 330000, China.

Received: 8 November 2017 Accepted: 18 January 2018

Published online: 02 February 2018

\section{References}

1. Wang QP, Wu ZD, Wei J, Owen RL, Lun ZR. Human Angiostrongylus cantonensis: an update. Eur J Clin Microbiol Infect Dis. 2012;31:389-95.

2. LV S, Zhang $Y$, Steinmann $P$, Zhou XN. Emerging angiostrongyliasis in mainland China. Emerg Infect Dis. 2008:14:161-4.

3. Al Hammoud R, Nayes SL, Murphy JR, Heresi GP, Butler IJ, Pérez N. Angiostrongylus cantonensis meningitis and myelitis, Texas, USA. Emerg Infect Dis. 2017;23:1037.

4. Nguyen Y, Rossi B, Argy N, Baker C, Nickel B, Marti H, Zarrouk V, Houzé S, Fantin B, Lefort A. Autochthonous case of eosinophilic meningitis caused by Angiostrongylus cantonensis, France, 2016. Emerg Infect Dis. 2017;23:1045.

5. Dalton MF, Fenton $\mathrm{H}$, Cleveland CA, Elsmo EJ, Yabsley MJ. Eosinophilic meningoencephalitis associated with rat lungworm (Angiostrongylus cantonensis) migration in two nine-banded armadillos (Dasypus novemcinctus) and an opossum (Didelphis virginiana) in the southeastern United States. Int J Parasitol Parasites Wildl. 2017:6:131.

6. Wang Q, Lai D, Zhu X, Chen X, Lun Z. Human angiostrongyliasis. Lancet Infect Dis. 2008:8:621-30.

7. McBride A, Chau T, Hong N, Mai N, Anh NT, Thanh TT, Van TTH, Xuan LT, Sieu T, Thai LH, et al. Angiostrongylus cantonensis is an important cause of eosinophilic meningitis in Southern Vietnam. Clin Infect Dis. 2017;64:1784-7.

8. Kumar V, Kyprianou I, Keenan JM. Ocular Angiostrongyliasis: removal of a live nematode from the anterior chamber. Eye (Lond). 2005:19:229-30.

9. Hidelaratchi MD, Riffsy MT, Wijesekera JC. A case of eosinophilic meningitis following monitor lizard meat consumption, exacerbated by anthelminthics. Ceylon Med J. 2005;50:84-6.

10. Loke P, AS MD, Robb A, Maizels RM, Allen JE. Alternatively activated macrophages induced by nematode infection inhibit proliferation via cellto-cell contact. Eur J Immunol. 2000;30:2669-78.

11. Reece JJ, Siracusa MC, Scott AL. Innate immune responses to lung-stage helminth infection induce alternatively activated alveolar macrophages. Infect Immun. 2006;74:4970-81.

12. Du L, Wei H, Li L, Shan H, Yu Y, Wang Y, Zhang G. Regulation of recombinant Trichinella spiralis 53-kDa protein (rTsP53) on alternatively activated macrophages via STAT6 but not IL-4Ralpha in vitro. Cell Immunol. 2014;288:1-7.

13. Xu J, Zhang H, Chen L, Zhang D, Ji M, Wu H, Wu G. Schistosoma japonicum infection induces macrophage polarization. J Biomed Res. 2014;28:299-308.

14. Mohrs K, Harris DP, Lund FE, Mohrs M. Systemic dissemination and persistence of Th2 and type 2 cells in response to infection with a strictly enteric nematode parasite. J Immunol. 2005;175:5306-13.

15. Gieseck RR, Wilson MS, Wynn TA. Type 2 immunity in tissue repair and fibrosis. Nat Rev Immunol. 2018;18:62-76.

16. Kopf M, Brombacher F, Hodgkin PD, Ramsay AJ, Milbourne EA, Dai WJ, Ovington KS, Behm CA, Kohler G, Young IG, Matthaei KI. IL-5-deficient mice have a developmental defect in CD5+ B-1 cells and lack eosinophilia but have normal antibody and cytotoxic T cell responses. Immunity. 1996;4:15-24.

17. Mishra A, Rothenberg ME. Intratracheal IL-13 induces eosinophilic esophagitis by an IL-5, eotaxin-1, and STAT6-dependent mechanism. Gastroenterology. 2003;125:1419-27.

18. Ramalingam T, Rajan B, Lee J, Rajan TV. Kinetics of cellular responses to intraperitoneal Brugia pahangi infections in normal and immunodeficient mice. Infect Immun. 2003;71:4361-7.

19. Weller PF. Eosinophils: structure and functions. Curr Opin Immunol. 1994:6:85-90.

20. Sehmi R, Wardlaw AJ, Cromwell O, Kurihara K, Waltmann P, Kay AB. Interleukin-5 selectively enhances the chemotactic response of eosinophils obtained from normal but not eosinophilic subjects. Blood. 1992;79:2952-9.

21. Rothenberg ME, MacLean JA, Pearlman E, Luster AD, Leder P. Targeted disruption of the chemokine eotaxin partially reduces antigen-induced tissue eosinophilia. J Exp Med. 1997;185:785-90.

22. Humbles AA, Lu B, Friend DS, Okinaga S, Lora J, Al-Garawi A, Martin TR, Gerard NP, Gerard C. The murine CCR3 receptor regulates both the role of 
eosinophils and mast cells in allergen-induced airway inflammation and hyperresponsiveness. Proc Natl Acad Sci U S A. 2002;99:1479-84.

23. Gurish MF, Humbles A, Tao H, Finkelstein S, Boyce JA, Gerard C, Friend DS, Austen KF. CCR3 is required for tissue eosinophilia and larval cytotoxicity after infection with Trichinella spiralis. J Immunol. 2002;168:5730-6.

24. Owhashi M, Arita H, Hayai N. Identification of a novel eosinophi chemotactic cytokine (ECF-L) as a chitinase family protein. J Biol Chem. 2000;275:1279-86.

25. Wu F, Wei J, Liu Z, Zeng X, Yu Z, Lv Z, Sun X, Wu Z. Soluble antigen derived from IV larva of Angiostrongylus cantonensis promotes chitinase-like protein 3 (Chil3) expression induced by interleukin-13. Parasitol Res. 2016;115:3737-46.

26. Qin H, Holdbrooks AT, Liu Y, Reynolds SL, Yanagisawa LL, Benveniste EN. SOCS3 deficiency promotes M1 macrophage polarization and inflammation. J Immunol. 2012;189:3439-48.

27. Maazi H, Patel N, Sankaranarayanan I, Suzuki Y, Rigas D, Soroosh P, Freeman GJ, Sharpe AH, Akbari O. ICOS:ICOS-ligand interaction is required for type 2 innate lymphoid cell function, homeostasis, and induction of airway hyperreactivity. Immunity. 2015;42:538-51.

28. Kerzerho J, Maazi H, Speak AO, Szely N, Lombardi V, Khoo B, Geryak S, Lam J, Soroosh P, Van Snick J, Akbari O. Programmed cell death ligand 2 regulates $\mathrm{TH} 9$ differentiation and induction of chronic airway hyperreactivity. J Allergy Clin Immunol. 2013;131:1048-57. 1051-1057

29. Yu L, Liao Q, Zeng X, Lv Z, Zheng H, Zhao Y, Sun X, Wu Z. MicroRNA expressions associated with eosinophilic meningitis caused by Angiostrongylus cantonensis infection in a mouse model. Eur J Clin Microbiol Infect Dis. 2014;33:1457-65.

30. Liu Z, Wu Y, Feng Y, Wu F, Liu R, Wang L, Liang J, Liu J, Sun X, Wu Z. Spleen atrophy related immune system changes attributed to infection of Angiostrongylus cantonensis in mouse model. Parasitol Res. 2017;116:577-87.

31. Huang SC, Everts B, Ivanova Y, O'Sullivan D, Nascimento M, Smith AM, Beatty W, Love-Gregory L, Lam WY, O'Neill CM, et al. Cell-intrinsic lysosomal lipolysis is essential for alternative activation of macrophages. Nat Immunol. 2014;15:846-55.

32. Yu L, Wu X, Wei J, Liao Q, Xu L, Luo S, Zeng X, Zhao Y, Lv Z, Wu Z. Preliminary expression profile of cytokines in brain tissue of BALB/C mice with Angiostrongylus cantonensis infection. Parasit Vectors. 2015:8:328.

33. Katare S, Bhan A, Caruthers JM, Delgass WN, Venkatasubramanian V. A hybrid genetic algorithm for efficient parameter estimation of large kinetic models. Comput Chem Eng. 2004;28:2569-81.

34. Sun X, Bao J, Nelson KC, Li KC, Kulik G, Zhou X. Systems modeling of anti-apoptotic pathways in prostate cancer: psychological stress triggers a synergism pattern switch in drug combination therapy. PLoS Comput Biol. 2013:9:e1003358.

35. Zhao J, Lv Z, Wang F, Wei J, Zhang Q, Li S, Yang F, Zeng X, Wu X, Wu Z. $Y m 1$, an eosinophilic chemotactic factor, participates in the brain inflammation induced by Angiostrongylus cantonensis in mice. Parasitol Res. 2013;112:2689-95.

36. Geissmann F, Jung S, Littman DR. Blood monocytes consist of two principal subsets with distinct migratory properties. Immunity. 2003;19:71-82.

37. King IL, Dickendesher TL, Segal BM. Circulating Ly-6C+ myeloid precursors migrate to the CNS and play a pathogenic role during autoimmune demyelinating disease. Blood. 2009;113:3190-7.

38. Ajami B, Bennett JL, Krieger C, McNagny KM, Rossi FM. Infiltrating monocytes trigger EAE progression, but do not contribute to the resident microglia pool. Nat Neurosci. 2011;14:1142-9.

39. Ma $Y$, Li $Y$, Jiang $L$, Wang $L$, Jiang $Z$, Wang $Y$, Zhang $Z$, Yang GY. Macrophage depletion reduced brain injury following middle cerebral artery occlusion in mice. J Neuroinflammation. 2016;13:38.

40. Kobayashi T, lijima K, Radhakrishnan S, Mehta V, Vassallo R, Lawrence CB, Cyong JC, Pease LR, Oguchi K, Kita H. Asthma-related environmental fungus, Alternaria, activates dendritic cells and produces potent Th2 adjuvant activity. J Immunol. 2009;182:2502-10.

41. Denis O, van den Brule S, Heymans J, Havaux X, Rochard C, Huaux F, Huygen K. Chronic intranasal administration of mould spores or extracts to unsensitized mice leads to lung allergic inflammation, hyper-reactivity and remodelling. Immunology. 2007;122:268-78.

42. Lawrence T, Natoli G. Transcriptional regulation of macrophage polarization: enabling diversity with identity. Nat Rev Immunol. 2011;11:750-61.
43. Satoh T, Takeuchi O, Vandenbon A, Yasuda K, Tanaka Y, Kumagai Y, Miyake T, Matsushita K, Okazaki T, Saitoh T, et al. The Jmjd3-Irf4 axis regulates M2 macrophage polarization and host responses against helminth infection. Nat Immunol. 2010;11:936-44.

44. Ahmadian M, Suh JM, Hah N, Liddle C, Atkins AR, Downes M, Evans RM. PPARgamma signaling and metabolism: the good, the bad and the future. Nat Med. 2013;19:557-66.

45. Ye $\mathrm{S}, \mathrm{Xu} \mathrm{H}$, Jin J, Yang M, Wang C, Yu Y, Cao X. The E3 ubiquitin ligase neuregulin receptor degradation protein 1 (Nrdp1) promotes M2 macrophage polarization by ubiquitinating and activating transcription factor CCAAT/enhancer-binding Protein beta (C/EBPbeta). J Biol Chem. 2012;287:26740-8.

46. Kapoor N, Niu J, Saad Y, Kumar S, Sirakova T, Becerra E, Li X, Kolattukudy PE. Transcription factors STAT6 and KLF4 implement macrophage polarization via the dual catalytic powers of MCPIP. J Immunol. 2015;194:6011-23.

47. Chang NC, Hung SI, Hwa KY, Kato I, Chen JE, Liu CH, Chang AC. A macrophage protein, $Y m 1$, transiently expressed during inflammation is a novel mammalian lectin. J Biol Chem. 2001;276:17497-506.

48. Zhao A, Urban JJ, Anthony RM, Sun R, Stiltz J, van Rooijen N, Wynn TA, Gause WC, Shea-Donohue T. Th2 cytokine-induced alterations in intestinal smooth muscle function depend on alternatively activated macrophages. Gastroenterology. 2008;135:217-25.

49. Voehringer D, van Rooijen N, Locksley RM. Eosinophils develop in distinct stages and are recruited to peripheral sites by alternatively activated macrophages. J Leukoc Biol. 2007;81:1434-44.

50. Oeser K, Maxeiner J, Symowski C, Stassen M, Voehringer D. T cells are the critical source of IL-4/IL-13 in a mouse model of allergic asthma. Allergy. 2015;70:1440-9.

51. Kuperman DA, Schleimer RP. Interleukin-4, interleukin-13, signal transducer and activator of transcription factor 6, and allergic asthma. Curr Mol Med. 2008;8:384-92.

52. Falcone FH, Loke P, Zang X, MacDonald AS, Maizels RM, Allen JE. A Brugia malayi homolog of macrophage migration inhibitory factor reveals an important link between macrophages and eosinophil recruitment during nematode infection. J Immunol. 2001;167:5348-54.

53. Mclnnes IB, Leung BP, Harnett M, Gracie JA, Liew FY, Harnett W. A novel therapeutic approach targeting articular inflammation using the filarial nematode-derived phosphorylcholine-containing glycoprotein ES-62. J Immunol. 2003:171:2127-33.

54. Lumb FE, Doonan J, Bell KS, Pineda MA, Corbet M, Suckling CJ, Harnett MM, Harnett W. Dendritic cells provide a therapeutic target for synthetic small molecule analogues of the parasitic worm product, ES-62. Sci Rep. 2017;7:1704.

55. Coltherd JC, Rodgers DT, Lawrie RE, Al-Riyami L, Suckling CJ, Harnett W, Harnett MM. The parasitic worm-derived immunomodulator, ES-62 and its drug-like small molecule analogues exhibit therapeutic potential in a model of chronic asthma. Sci Rep. 2016;6:19224.

56. Rodgers DT, Pineda MA, Suckling CJ, Harnett W, Harnett MM. Drug-like analogues of the parasitic worm-derived immunomodulator ES-62 are therapeutic in the MRL/Lpr model of systemic lupus erythematosus. Lupus. 2015;24:1437-42.

57. Aprahamian TR, Zhong X, Amir S, Binder CJ, Chiang LK, Al-Riyami L, Gharakhanian R, Harnett MM, Harnett W, Rifkin IR. The immunomodulatory parasitic worm product ES-62 reduces lupus-associated accelerated atherosclerosis in a mouse model. Int J Parasitol. 2015;45:203-7.

58. Klaver EJ, Kuijk LM, Laan LC, Kringel H, van Vliet SJ, Bouma G, Cummings RD, Kraal G, van Die I. Trichuris suis-induced modulation of human dendritic cell function is glycan-mediated. Int J Parasitol. 2013;43:191-200.

59. Wang L, Xie H, Xu L, Liao Q, Wan S, Yu Z, Lin D, Zhang B, Lv Z, Wu Z, Sun X. rSj16 protects against DSS-induced colitis by inhibiting the PPAR-alpha signaling pathway. Theranostics. 2017;7:3446-60. 